\title{
Religión y política en el Uruguay
}

Nicolás Guigou*

\section{Sobre religión y política en el Uruguay (a modo de presentación)}

En la división social del trabajo intelectual, existen objetos de indagación y análisis que parecen poseer un valor agregado, un prestigio aurético que los vuelve valiosos por sí mismos. Tal parece ser el caso tanto de los objetos que alberga la dimensión política, como de los saberes que se preocupan (y analíticamente construyen) a la misma. La fetichización de un mundo de la polis, de un mundo pues político, ha requerido para su señalización y diseño de variados ejercicios de separación. Bajo esta separatividad, es que el mundo político suele presentarse en tanto autónomo, o en todo caso, limitado en su autonomía ("autonomía relativa") por diferentes determinantes, todas ellas signadas por una preclara des-religiosidad.

Esta imagen ilustra al menos los consensos implícitos entre aquellos investigadores uruguayos que se dedican al estudio de la política y de la religión - dos ámbitos claramente diferenciados - y que puede sintetizarse en la consigna de que "política y religión no se juntan".

* Prof. Adj. Mag. L. Nicolás Guigou. Cátedra de Antropología Cultural, Liccom, Universidad de la República. Docente e investigador, Dpto. de Antropología Social, Fhce, Udelar, Montevideo, Uruguay. Doctorando, Ppgas, Ufrgs, bolsista CNPq. www.antropologiasocial.org.uy.

\begin{tabular}{|l|l|l|l|l|l|}
\hline Civitas & Porto Alegre & v. 6 & n. 2 & jul.-dez. 2006 & p. 43-54 \\
\hline
\end{tabular}


Digamos que, para el caso uruguayo y desde la academia, la política constituye un objeto noble de estudio, en cuanto la religión es una dimensión interesante de la cultura, mas sin ninguna incidencia política.

Podría decirse que desde un cierto sentido común académico, aquellos investigadores que se dedican al estudio de la religión en el Uruguay, están frente a un objeto dudoso, tal vez un remanente del proceso civilizatorio uruguayo

Esta visión, sin duda, ha dificultado los estudios sobre las religiones en Uruguay, pero, sobre todo, ha presentado límites a los enfoques sobre los distintos elementos que conforman la dimensión política - particularmente en sus continuidades simbólicas, ritualísticas y performáticas - más difíciles de ser indagados desde el instrumental clásico de las propias disciplinas dedicadas a esta temática.

No en vano, varios de nosotros - me refiero a investigadores uruguayos de la religión- hemos venido utilizando el concepto de religión civil ${ }^{l}$ para tratar de establecer un espacio de suturas en el conjunto de significaciones y prácticas religioso-políticas que hacen en buena parte comprender por qué en Uruguay son sagrados el Parlamento, la democracia y hasta los períodos presidenciables.

Desde las diferentes miradas teóricas que convoca esta religión civil, no resulta extraño comprender que el Uruguay se encuentre en primer lugar dentro de Latinoamérica en relación a la adhesión democrática de sus habitantes, tal como lo advierte el informe "La Democracia en América Latina: hacia una democracia de Ciudadanas y Ciudadanos", realizado en el año 2004 por el Programa de Naciones Unidas para el Desarrollo (Pnud).

Asimismo, la perdurabilidad temporal de esta religión civil uruguaya digamos, la absorción mitopráctica del acontecimiento - pudo visibilizarse con claridad en tanto sociología situacional del significado (Sahlins, 1985) durante el conjunto de crisis socio-económicas que vivió este país bajo el gobierno del anterior Presidente de la República, Jorge Batlle (mar. 2000 mar. 2005) y que se radicalizaran en el año 2002.

Refiero-me principalmente a los aportes de Bayce, Caetano, Da Costa, Geymonat y Guigou. Ver: Guigou (3003 - edición en internet: www.antropologiasocial.org.uy; 2000.). 
La mera posibilidad planteada por algunos opositores políticos de remover al Presidente frente a la gravedad de la situación, cayó en un vacío cercano al horror. Es que si la democracia era y es sagrada - digamos, la cristalización máxima de la racionalidad ciudadana - la misma debe ser cuidada desde esa racionalidad.

La posibilidad, insistamos, de remover a un Presidente electo democráticamente sin que finalizara el período fijado por la Constitución, habría implicado quebrar con el consensualismo (también como expresión de esa racionalidad ciudadana). Este quiebre - continuemos con la mirada nativa - hubiera llevado también a un caos, a una situación imprevisible, $y$, principalmente, a renunciar a "las reglas" de convivencia democrática.

Una perspectiva nativa que repitió pues esquemas de orientación y acción política, construidos históricamente y que son parte de las mitologías de la nación (el Uruguay “esencialmente democrático").

Ese esencialismo democrático - mitologías de la nación que conforman al sujeto-ciudadano - se nutre entre otros elementos, de un conjunto de recreaciones historiográficas, del discurso y las prácticas políticas, y de, por supuesto, los textos escolares (Guigou, 2000; 2004). La actualización de la escritura-inscripción de estas mitologías, colaboró en buena parte a generar las condiciones para que en el marco de tamaña crisis, fueran mayoritariamente rechazados tanto los incipientes desbordes sociales, como los intentos represivos desde esferas gubernamentales.

Los (leves) movimientos hacia un proceso de radicalización y choque social, fueron rápidamente neutralizados y los discursos tanto como las prácticas políticas tendieron a estrategias de hiperintegración (simbólicas y materiales) cuya cristalización redundó en el triunfo de una amplia alianza de izquierda que ganó cómodamente las elecciones nacionales de 2004, con más de la mitad de los votos y en la primera vuelta del balotaje electoral.

Y dado que el tiempo pos-político no es el tiempo uruguayo (por lo menos por ahora), las modalidades que podríamos llamar de ciudadanía directa principalmente de corte plebiscitario - no dejan de poseer también su manto de sacralidad. 


\section{Más allá de la religión civil}

Pero debemos reflexionar más allá - también más acá - de los esencialismos propios a la religión civil uruguaya. Si acaso la palabra-clave - "religión civil" - puede establecer una articulación semántica entre religión y política - la política en tanto expresión de esa religión civil uruguaya no sería entonces la cristalización de una supuesta (y mítica) racionalidad social, ni la religión sería un objeto antiguo, más allá de la racionalidad -, la misma no agota el conjunto de relaciones posibles entre una y otra. En primer lugar, la religión civil - los mitos, las representaciones emblemáticas y los valores que la sustentan - constituye parte justamente de los posibles socio-históricos que se han establecido en Uruguay en esa trama conformada por la relación entre religión y política.

Pero como toda relación histórica, la misma cambia y se transforma.

Así, la privatización de lo religioso en Uruguay - parte de los efectos de un radical proceso de secularización y laicización ocurrido desde mediados y finales del siglo 19 hasta aproximadamente la década de los ' 30 del siglo $20^{2}$ - y la elaboración de una religión civil "jacobina”, sustitutoria y homogeneizadora, matrizó sin duda la conformación de la nación en cuestión.

Esta situación histórica, que devino en matriz cultural y que resulta tan importante para abrevar en la configuración cultural uruguaya, puede ser comparable con el trasfondo religioso brasileño, o bien con el "catolicismo de estado" argentino, de particular incidencia en la arena política de este país desde la década de los ' 30 del siglo pasado.

El trazado diferente de las conexiones entre religión y política para cada una de estas naciones, no debe hacernos olvidar que estas matrices culturales no solamente se actualizan, sino que cambian en el marco de profundas transformaciones.

Así, el laicismo privatizador de corte anticlerical, que llevó inclusive - y no hace mucho tiempo - a discutir en el Parlamento la presencia de una cruz en el espacio público - nos referimos a la popularmente conocida como "Cruz del Papa", emplazada en homenaje a la primera visita oficial de Juan

2 Ver sobre este corte temporal: Guigou (2003); Caetano y Geymonat (1997). 
Pablo II al Uruguay (vd. Caetano, 1994; Guigou, 2002), puede resultar extraña fuera de la comprensión cultural de esta dinámica jacobina. Este debate procesado a finales de los ' 80 - y el mantenimiento de la citada cruz en el espacio público, mostró a su vez la última gestualidad de una religión civil sustitutoria que había tratado de aunar igualdad con homogeneidad.

Al mismo tiempo, dejar fuera de consideración las discusiones que desde esferas gubernamentales y no gubernamentales transcurren en torno a las peculiaridades del caro laicismo uruguayo (un modelo aún más radical que el francés) ${ }^{3} \mathrm{u}$ obviar que actualmente nos encontramos con un laicismo mucho más atento a las diferencias, nos llevaría a desconocer los cambios transcurridos en por lo menos los últimos quince años.

Existen, también, otros aspectos para reflexionar sobre el diálogo entre religión y política. Si la incidencia de nuestra religión civil sustitutoria significó históricamente la privatización de las singularidades religiosas, esto no quiere decir que lo religioso desapareciera del espacio público, ni que en la contemporaneidad uruguaya (bastaría pensar en la populosa fiesta en honor a Yemanjá el dos de febrero de cada año), las diferentes manifestaciones religiosas no tengan su presencia importante en el espacio del ágora.

Asimismo, los conceptos de público y privado, pueden situarse únicamente desde su transversalidad - cuando no desde su producción real en tanto derivas de la citada religión civil - ya que se tratan de alusiones teóricas a espacios de influencia mutua, y no de dimensiones desconectadas.

En general - y para el caso uruguayo -, estamos mucho más dispuestos a aceptar el jacobinismo de Estado, que, por ejemplo, la influencia de diferentes concepciones religiosas en las elites políticas, la importancia de partidos políticos con una relevante impronta religiosa dentro de la escena nacional, la

3 El tema del laicismo en la educación puede ser un buen indicador. Tal como lo indica Da Silveira (1995), los países europeos como Bélgica, Holanda, Alemania, poseen diferentes formas de promover la enseñanza religiosa en las escuelas públicas, o subvencionan la enseñanza religiosa privada. Inclusive en Francia (paradigma del laicismo) el Estado francés subvenciona el $90 \%$ de las escuelas privadas (la mayoría católicas) o permite la presencia de símbolos religiosos en las escuelas públicas de Estrasburgo y en los departamentos de Ultramar. En el Uruguay, las subvenciones no existen, y la enseñanza en las escuelas públicas es rigurosamente prohibida desde 1909. 
influencia de diferentes corrientes de fe en la constitución de movimientos sociales, o, en fin, algunas correlaciones entre opciones religiosas y políticas.

También, muchas veces, escapa al análisis el papel que algunas instituciones religiosas - especialmente la Iglesia Católica - tienen en la arena política a través de un complejo proceso de elaboración de una suprapoliticidad, que bien podríamos llamar de "suprapoliticidad trascendente", y que interviene fuertemente en los actuales debates sobre políticas económicas, orientación sexual, legalización del aborto, etc.

Este conjunto de elementos - y la lista podría continuar - intentan ilustrar que las relaciones entre religión y política son en Uruguay mucho más complejas (y menos extrañas) de lo que puede mostrar un análisis inicial.

Pero existe un elemento que parece estar por encima de todos los mencionados: la inscripción que la religión ha dejado en la política (y la política en la religión) en tanto universos separados, en tanto conjunto de significaciones no comparables y contrarias, que deben luchar permanentemente por su diferenciación. De este modo, establecer que los partidos políticos que tuvieron (y todavía tienen) anhelos vanguardistas y que construyeron una visión del mundo totalizadora - y un estilo militante - pueden ser llamados de verdaderos portadores de "religiones políticas" o decir que la naturalización de la democracia en Uruguay tiene una estrecha relación con su sacralidad, nos coloca en esa sutura entre dos regiones de significaciones, llamadas de religión y de política.

\section{Otras miradas}

Ahora bien, esta sutura entre religión y política parece resultar un tanto molesta. La episteme liberal - siguiendo aquí una expresión cara a Burity (Burity, 2000) - constituye parte de nuestra episteme moderna, aquella que el perspectivismo foucaultiano coloca como lugar privilegiado de emergencia de la figura del hombre en tanto objeto y sujeto del saber.

Esta figura del saber es también la figura del sujeto-ciudadano: un sujeto autónomo, independizado de todo orden trascendental, racional y dueño de su destino aquí en la tierra. 
Esta ilusión de autonomía, este compleja operativa que transforma al humano en objeto, desacralizándolo, extrayéndolo de cualquier orden trascendental al mismo tiempo que transformándolo en lugar del discurso y del saber de las ciencias humanas - en definitiva, de nuestra mirada -, acompaña también ese otro ejercicio de resacralización racional-ciudadana.

Es justamente desde ese ver/decir que resulta complejo establecer el locus, el lugar del discurso teológico-político que (ecos de Spinoza) vuelve a ser planteado por algunos pesquisadores - se trate de Laclau o Corten -, en tanto horizonte posible de sentido de nuestra contemporaneidad.

Tal vez el ingreso del neopentecostalismo al Uruguay, su reformulación del campo religioso y por supuesto del evangélico, pueda ser de utilidad para seguir esa sutura, ese discurso teológico-político al menos en algunos niveles.

\section{Neopentecostales}

Desde la década de los ' 80 y los '90 asistimos en Uruguay al arribo y localización de corrientes neopentecostales - principalmente de origen brasileño - que han modificado profundamente la escena pública de la polis.

En la larga marcha hacia la desprivatización de lo religioso en Uruguay, el neopentecostalismo brasileño - representado inicialmente por la Iglesia Dios de Amor y posteriormente y con peculiar énfasis, por la Iglesia Universal del Reino de Dios - ha tenido un lugar definitivo, en tanto transformador de la lengua política. El neopentecostalismo, en tanto fuerza que permite atrae un devenir de aceptabilidad y enunciabilidad de aquello que era inaceptable (y no enunciable) se vuelve una fuerza de transformación, una fuerza de transformación de la lengua política, al decir de Corten (1996).

Ahora bien, esta transformación de la lengua política, desborda el discurso religioso y en ese sentido "neopentecostaliza" la lengua política., generando diversos efectos. Veamos: la "efectología" de la religión civil uruguaya consistió - todavía consiste - en la obliteración (entiéndase bien) de las identidades religiosas en el ágora en tanto identidades políticas.

Dentro de las formas de clasificación que augura una "religión cívica" como le llama Bourdieu (1997), la imposibilidad de asunción de una continuidad teológico-política aún supone para el caso uruguayo, el anhelo de una 
abstracción democrática totalizadora, por encima de las singularidades o particularidades culturales.

Es por esto que cualquier discusión sobre el laicismo en Uruguay deberá basarse en la lucha de un universal general positivo - el sujeto ciudadano contra los particularismos culturales, que, en todo caso, bien pueden circular por lo privado y asomarse (de manera acotada) al espacio del ágora. El neopentecostalismo transformó esta dinámica, mostrando algunas de las aristas del "malestar en la democracia formal", para parafrasear a Zizek (2000). La constitución de una máquina narrativa (Corten, 1996) retomó el mal - el mal elaborado por los creyentes de la polis - que, como significante vacío, ha podido alimentarse de improntas varias. Este mal ya estaba en las proyecciones de la polis, en la lengua política, en esa eterna escenificación de la expulsión social de lo social irrealizado.

En pleno terreno de la inmanencia - y después de cierta modalidad aurética y trascendental que lo político supo poseer -, el neopentecostalismo advino como máquina narrativa, como máquina interpretante, que logró dar cuenta de la inmanencia del sufrimiento, adentrarse en sus nervaduras a través de la emoción, expresar sus límites en ese no-lugar del discurso glosolálico, y configurar una totalidad, con efectos en identidades sociales varias.

En Uruguay, las paradojas de la religión civil, muestran aquel límite constituyente que Zizek observa entre la democracia antisustancialista, basada en una pretensión imposible de la ciudadanía abstracta que supone el olvido (también imposible) de los lazos "primarios", y la singularidad cultural de la "cosa nacional", del Estado-Nación, que, lejos de conformar un "resto" de esta abstracción, la habilita (Zizek, 2000).

Si acaso en Uruguay el mapa coincide con el territorio, es por el largo trabajo histórico-mitopráctico de hacer coincidir la "cosa nacional" con la democracia (y de ahí su esencialización). Frente a una cartografía políticareligiosa tan densa, el neopentecostalismo - y particularmente la presencia de la Iglesia Universal del Reino de Dios - vino a alterar el espejo, el nodo de esta conexión.

$\mathrm{Al}$ establecer su performance mediática y sus formas de apropiarse de la ciudad (y de los espacios céntricos), al producir sus discursos polifónicos desde la emoción postulando el sufrimiento como eje discursivo de entrada y 
de salida, al representar, en fin, el mal desde la inmanencia como una totalidad, los "Pare de sufrir" - como peyorativamente los denominan algunos líderes umbandistas - lograron anidar en esa autonomización del sujetociudadano, aunque bajo otras características. No pues mediante las promesas de un progreso indeclinable producto de un mítico ethos democrático, sino desde el establecimiento de diferentes identidades en la polis a través de la interpretación y sobreinterpretación del sufrimiento, de las pistas de sentido que hacen que el mal se llene de imágenes y contenidos. Y claro, de la victoria.

La victoria - corolario de la desvictimización de los sufrientes - recupera esa autonomía y la revierte extrayéndola de la pura negatividad alimentada por exclusiones de todo orden, pulverización de tradiciones culturales y desintegración de lazos sociales. Densidad de la religión civil uruguaya, las elegías a la victoria en el recorrido político y religioso serán con todo diferentes, y con otras modalidades de continuidad.

Ahondemos en un ejemplo: en Uruguay, la relación entre Iglesias neopentecostales y frente políticos-electores resulta puntual y acotada. Para el caso del mundo fragmentado de iglesias neopentecostales y pentecostales, encontramos algunas participaciones en movimientos sociales. Pero estas continuidades religioso-políticas no se encontrarán al estilo brasileño. No hay pues bancadas evangélicas, ni tampoco diferentes nominaciones del universo pentecostal disputando posiciones en la arena política.

\section{El mal a la uruguaya}

Es en la inmanencia del mal que logra su expresión en un corpus polimórfico (y mutante) de demonios a expulsar, es en la conflictiva "guerra religiosa", que encontramos las derivas típicas que puede asumir una confrontación de este tipo en Uruguay: la trastocación del espacio público y la invocación de las mitologías igualitarias de la religión civil (que en su discurso, atrae las diferencias de las singularidades religiosas, para concebirlas o bien en el ámbito privado, o bien bajo la modalidad democrática de la aceptabilidad de la diferencia).

Tal vez para encontrar ecos históricos de algo similar a una guerra religiosa "a la uruguaya", debamos retrotraernos a finales del siglo 19 y princi- 
pios del siglo 20, y a la lucha entre católicos y protestantes "históricos" (Geymonat, 2004), considerando la afiliación de estos últimos al proyecto anticlerical del Estado-Nación.

Pero la actual guerra religiosa - centrada particularmente entre la Iglesia Universal del Reino de Dios y corrientes afro-brasileñas - corre bajo otros signos: se trata del conflicto entre singularidades religiosa que no buscan "ecumenizar" sus diferencias, y mucho menos, colaborar a la generación de un ámbito público abstracto como garantía de alguna dialogicidad.

Desde esta singularidad, la Iglesia Universal particularmente ha colaborado a "neopentecostalizar" el discurso político, no únicamente en el sentido más amplio de participar de una estética emocional y una "razón populista" (Laclau, 2005) a través de la cual toda la gestualidad de una supuesta racionalidad política se desarma, sino en el lugar más terrenal de alineamientos confrontacionales de corrientes afro-brasileñas, que aúnan un discurso múltiple religioso y a la vez político, bajo las letanías (e invocaciones varias) de la religión civil uruguaya en tanto expresión de derechos - y pensemos en la palabra que sigue - "consagrados".

Si la Iglesia Universal del Reino de Dios no ha tenido en Uruguay choques con el Estado, su instalación con todo no ha sido tan fácil y continúa siendo acompañada por diferentes críticas provenientes del propio campo religioso, periodístico e intelectual (digamos, que desde este último lugar, el termino "alienación" cada tanto tiempo aparece, o el más foucaultiano de "disciplinamiento", para tratar de dar cuenta de esta especificidad neopentecostal).

En esa espacialidad del conflicto, en esas inscripciones múltiples del discurso político-religioso es que encontramos a las letanías de la religión civil uruguaya, como un espectro que ha de ser invocado en la trama confrontacional (y relacional) de la disputa neopentecostal/afro-brasileña.

Esta trama, esta intersección muestra que la "guerra religiosa" sigue transcurriendo sobre el suelo firme de las mitologías de la religión civil.

En esta movilización mitológica, la mediatización ampliada de la Iglesia Universal del Reino de Dios y su tematización en el campo periodístico e intelectual, posee su lugar de actualización mediante las reflexiones acerca del lugar de lo religioso en lo público, su supuesto desborde, la alteración que 
conlleva esta ruptura de límites de un deber-ser público desprovisto de esa traza indeleble que marca ahora a las singularidades religiosas desde el extraño lugar de la confrontación.

\section{Guerras religiosas y religión civil}

La guerra religiosa se vuelve así debate público, debate de la polis, interpelando las mitologías de la igualdad - tan caras a la religión civil - y problematizando el lugar de las especificidades religiosas en sus recorridos ciudadanos.

La religión civil uruguaya había optado por la privatización de las opciones religiosas, con lo cual los enfrentamientos entre unas y otras no trascendían la esfera de lo privado. A diferencia de la religión civil americana, cuya secularización y desdogmatización de los contenidos de fe había permitido la elaboración de una continuidad entre las "religiones fundacionales" y los valores que permearon (y permean) a la nación americana, la religión civil uruguaya tentó ser substitutiva de las diferentes manifestaciones religiosas, particularmente en lo que se refiere al espacio público.

La paradoja de esta religión civil parece estar conformadas en la contemporaneidad, por la aceptación de singularidades religiosas, cuya conflictividad no es azarosa sino estructural, y cuyo ingreso y redefinición de lo público pasan por la propia confrontación. En esos límites, en ese espacio liminal es que también parece jugarse uno de los lugares constitutivos de los novedosos discursos teológicos-políticos uruguayos.

\section{Referencias}

BOURDIEU, Pierre. Espíritu de estado: génesis y estructura del campo burocrático. In: Idem Razones prácticas. Barcelona: Anagrama, 1997.

BURITY, Joanildo. Religião e política na fronteira: desinstitucionalização e deslocamento numa relação historicamente polêmica. VII Congreso Latinoamericano de Religión y Etnicidad, Padua, Italia, 2000.

CORTEN, André. Os pobres e o espirito santo. Petrópolis: Vozes, 1996.

CAETANO, Gerardo. La instalación pública de la llamada "Cruz del Papa" y los perfiles de un debate distinto. Montevideo: Obsur, 1994. 
CAETANO, Gerardo; GEYMONAT, Roger. La secularización uruguaya (18591919). Montevideo: Taurus, 1997.

DA SILVEIRA, Pablo. Laicidad, esa rareza. Revista Prisma, Montevideo, Ucudal, $\mathrm{n}^{\circ}$ 4, p. 154-185, 1995.

GEYMONAT, Roger. Protestantismo y secularización en el Uruguay. GEYMONAT, Roger. (Comp.) Las religiones en el Uruguay. Montevideo: Ed. La Gotera, 2004.

GUIGOU, L. Nicolás. De la religión civil: identidad, representaciones y mito-praxis en el Uruguay: algunos aspectos teóricos. In: ROMERO, Sonnia (Comp.) Anuario de Antropología Social y Cultural en Uruguay. Montevideo: Dpto. de Antropología Social, Fhce-Nordan, 2000.

GUIGOU, L. Nicolás. Mito-praxis: escuela pública y Estado-Nación en el Uruguay. Revista Hermes Criollo, Montevideo: v. 2, nº 2, mar.-jun. 2002.

GUIGOU, L. Nicolás. La nación laica: religión civil y mito-praxis en el Uruguay. Montevideo: Ed La Gotera, 2003.

LACLAU, Ernesto. La razón populista. Buenos Aires: FCE, 2005.

SAHLINS, Marshall. Islands of History. Chicago: The University of Chicago, 1985.

ZIZEK, Slajov. Mirando al sesgo. Buenos Aires: Paidós, 2000.

Recebido em 11 de agosto de 2006 e aprovado em 31 de agosto de 2006 